\title{
AARC Clinical Practice Guideline: Effectiveness of Pharmacologic Airway Clearance Therapies in Hospitalized Patients
}

\author{
Shawna L Strickland PhD RRT-NPS ACCS AE-C FAARC, \\ Bruce K Rubin MD MEngr MBA FAARC, Carl F Haas MLS RRT-ACCS FAARC, \\ Teresa A Volsko MHHS RRT FAARC, Gail S Drescher MA RRT, and \\ Catherine A O’Malley RRT-NPS
}

\begin{abstract}
Aerosolized medications are used as airway clearance therapy to treat a variety of airway diseases. These guidelines were developed from a systematic review with the purpose of determining whether the use of these medications to promote airway clearance improves oxygenation and respiratory mechanics, reduces ventilator time and ICU stay, and/or resolves atelectasis/consolidation compared with usual care. Recombinant human dornase alfa should not be used in hospitalized adult and pediatric patients without cystic fibrosis. The routine use of bronchodilators to aid in secretion clearance is not recommended. The routine use of aerosolized $\mathbf{N}$-acetylcysteine to improve airway clearance is not recommended. Aerosolized agents to change mucus biophysical properties or promote airway clearance are not recommended for adult or pediatric patients with neuromuscular disease, respiratory muscle weakness, or impaired cough. Mucolytics are not recommended to treat atelectasis in postoperative adult or pediatric patients, and the routine administration of bronchodilators to postoperative patients is not recommended. There is no high-level evidence related to the use of bronchodilators, mucolytics, mucokinetics, and novel therapy to promote airway clearance in these populations. Key words: airway clearance therapies; secretion clearance therapy; mucolytics; mucokinetics; heparin/N-acetylcysteine. [Respir Care 2015;60(7):1071-1077. (c) 2015 Daedalus Enterprises]
\end{abstract}

\section{Introduction}

The effectiveness of mucus clearance may be impaired by aging, tobacco use, environmental exposures, acute or

Dr Strickland is affiliated with the American Association for Respiratory Care, Irving, Texas. Dr Rubin is affiliated with the Children's Hospital of Richmond, Virginia Commonwealth University, Richmond, Virginia. $\mathrm{Mr}$ Haas is affiliated with the University of Michigan Health System, Ann Arbor, Michigan. Ms Volsko is affiliated with the Department of Respiratory Care, Akron Children's Hospital, Akron, Ohio. Ms Drescher is affiliated with MedStar Washington Hospital Center, Washington DC. Ms O'Malley is affiliated with the Ann \& Robert H Lurie Children's Hospital of Chicago, Chicago, Illinois.

Dr Rubin has disclosed relationships with GlaxoSmithKline, InspiRx, Fisher \& Paykel Healthcare, and Philips Respironics. Ms O'Malley has disclosed a relationship with Pari Respiratory Equipment. The other authors have disclosed no conflicts of interest.

Correspondence: Shawna L Strickland PhD RRT-NPS ACCS AE-C FAARC, American Association for Respiratory Care, 9425 North MacArthur Boulevard, Suite 100, Irving, TX 75063. E-mail: shawna. strickland@aarc.org.

DOI: $10.4187 /$ respcare. 04165 chronic airway diseases, inhalation injury, and trauma. ${ }^{1-3}$ Airway clearance depends on ciliary beat coordination and power, cough peak flow, and the bulk and surface properties of secretions. ${ }^{4}$ Various aerosolized medications have been used to improve airway clearance by altering mucus biophysical properties.

Recommending and administering medications for airway clearance therapy are within the respiratory therapist's scope of practice. Therapy should be matched to the patient's disease and therapy goals. The potential harmful effects associated with medication use and the cost of care are also important in this decision-making process. The therapist must be familiar with the evidence supporting the use of airway clearance therapy medications. However, there is little published evidence demonstrating the effectiveness of these medications. 5

Developed in conjunction with the systematic review by Sathe et al, ${ }^{5}$ this guideline is a companion to the 2013 AARC Clinical Practice Guideline. ${ }^{6}$ The purpose of this guideline is to provide guidance to clinicians in the identification, selection, and delivery of medication for airway clearance. This guideline does not include the use of medication for patients with cystic fibrosis, as this has been addressed. ${ }^{7}$ 
Table 1. Pharmacologic Airway Clearance Agents Included in This Systematic Review

\begin{tabular}{llll}
\hline \hline \multicolumn{1}{c}{$\beta$ Agonists } & Anticholinergics & Mucoactive Drugs & Novel Therapies \\
\hline Albuterol sulfate & Ipratropium bromide & N-Acetylcysteine & Inhaled heparin \\
Salbutamol & Oxitropium bromide & Dornase alfa & Inhaled heparin + N-acetylcysteine (burn cocktail) \\
Pirbuterol & Glycopyrrolate & Sodium bicarbonate & Albuterol + N-acetylcysteine \\
Levalbuterol & Tiotropium bromide & Guaifenesin & Inhaled tissue plasminogen activator \\
Salmeterol & & Mannitol & \\
Formoterol & & Hypertonic saline & \\
& & Normal saline & \\
\hline
\end{tabular}

\section{Assessment of Evidence}

This guideline focused on the effectiveness, harmful effects, and cost associated with the use of aerosolized medications for airway clearance therapy in hospitalized adult and pediatric patients without cystic fibrosis (CF); adult and pediatric patients with neuromuscular disease (NMD), respiratory muscle weakness, or impaired cough; and postoperative adult and pediatric patients. We sought to determine whether the use of these medications changes sputum properties, improves oxygenation, decreases ventilator time, decreases ICU stay, decreases readmissions or emergency department visits, improves pulmonary function, improves quality of life, or decreases infection frequency compared with usual care. We also sought to determine what harmful effects and complications might accompany the use of these drugs. The medications considered are listed in Table 1. Similar to what was described in the nonpharmacologic airway clearance therapy clinical practice guideline, ${ }^{6}$ no high-level evidence was available. Because the recommendations are based on low-level evidence, we did not use a formal guideline development process. Rather, the recommendations are based on a consensus of the committee, informed by a systematic review of the literature 5 and clinical experience. The systematic review helped frame the issues and allowed the identification of potential harmful effects.

\section{Hospitalized Adult and Pediatric Patients Without Cystic Fibrosis}

Trauma, inhalation injury, viral infections, asthma, bronchitis, and COPD can result in airway inflammation, mucus secretion, edema, and airway epithelium damage, which contribute to air-flow obstruction, air trapping, atelectasis, and ventilation/perfusion mismatch. ${ }^{8-11}$ Hypoxemia and increased work of breathing can contribute to respiratory insufficiency and failure, and intubation with mechanical ventilation can further compromise mucus clearance. Table 1 lists several medications often used to improve secretion clearance. These inhaled medications include bronchodilators, mucolytics to thin secretions, mucoregulators to reduce inflammation and mucus secretion, and expectorants to aid in cough clearance. ${ }^{12}$

In this systemic review, we found that the evidence from randomized controlled trials (RCTs) was weak and insufficient to support the use of medications to improve airway clearance, improve oxygenation, reduce ventilator time, reduce hospital stay, change sputum properties, improve quality of life, or improve respiratory mechanics compared with usual care. ${ }^{5} \mathrm{~A}$ retrospective cohort study in pediatric subjects evaluated the use of both heparin and $\mathrm{N}$-acetylcysteine in mechanically ventilated burn subjects. The results from this single-center study suggest that 5,000 units of aerosolized heparin alternating with $3 \mathrm{~mL}$ of $20 \%$ $\mathrm{N}$-acetylcysteine every $2 \mathrm{~h}$ for the first $7 \mathrm{~d}$ of injury lessen the need for re-intubation, ventilator time, and mortality in pediatric burn subjects. ${ }^{13}$ An RCT of 20 male subjects with chronic bronchitis or asthmatic bronchitis comparing aerosolized $\mathrm{N}$-acetylcysteine and isoproterenol reported decreased sputum viscosity (subjectively assessed), but no significant change in pulmonary function or daily sputum volume. ${ }^{14}$ The lack of high-level evidence from the studies included in this review does not support a recommendation for these therapies.

Guidelines from other groups support the use of medications such as inhaled short- and long-acting bronchodilators and inhaled corticosteroids for symptom relief in patients with symptomatic chronic obstructive pulmonary disorders. However, with respect to mucolytics and airway clearance, dornase alfa is not recommended for patients with non-CF bronchiectasis. ${ }^{15,16}$ Trials with clinically important outcome measures are needed to establish the evidence for mucoactive medications outside of CF. ${ }^{17}$

\section{Recommendations}

(1) Recombinant human dornase alfa should not be used in adults and children with non-CF bronchiectasis. (2) Routine use of bronchodilators to aid in secretion clearance is not recommended. (3) Routine use of aerosolized N-acetylcysteine to improve airway clearance is not recommended. 


\section{Adult and Pediatric Patients With Neuromuscular Disease, Respiratory Muscle Weakness, or Impaired Cough}

Respiratory complications are the leading cause of morbidity and mortality in patients with NMD and respiratory muscle weakness. ${ }^{18,19}$ Secretion retention is common in these patients and is primarily due to an inability to generate an effective cough. Cough is composed of 3 phases: inspiration, compression through glottic closure and contraction of abdominal and thoracic muscles, and forced exhalation. ${ }^{20}$ The interaction of these elements provides for a functional cough and expectoration of secretions. Inspiratory and abdominal muscle paralysis or weakness can inhibit the development of sufficient lung volumes and expiratory flow, respectively. ${ }^{21}$ Patients with NMD or stroke may also be unable to close the glottis to obtain adequate intrathoracic pressures, or breath stack for sufficient inspiratory volumes.

Compromised cough is common in many primary neurologic conditions and spinal cord injuries, but patients with spinal cord injuries may also suffer from mucus hypersecretion and an increase in bronchial tone. In cervical spinal cord injuries, parasympathetic overstimulation resulting from sympathetic denervation to the lungs leads to both an abnormal quantity and quality of mucus in the initial stages following injury. ${ }^{22}$

Although mucus clearance is preserved in NMD, ${ }^{23}$ patients with chronic respiratory infections from aspiration or retained secretions may develop a cycle of infection and inflammation that can impair ciliary function, cause airway remodeling, ${ }^{24}$ and alter the physical properties of secretions. ${ }^{12,25}$

Infants and children have chest-wall instability, lower functional residual capacity, and smaller airway diameter, which provide additional challenges for clearing airway secretions even in the absence of diseases that impair cough reflexes. ${ }^{26}$ The presence of NMD or motor neuron disease increases the propensity for pulmonary complications, morbidity, and mortality in this population.

No RCTs or other studies were found, of any quality, on the use of inhaled medications to enhance airway clearance in these patients. Although some organizations have recommended nonpharmacologic airway clearance therapies, ${ }^{27-29}$ only 2 guidelines recommend the use of inhaled medication for this purpose. ${ }^{29,30}$ Clinical practice guidelines from the Consortium for Spinal Cord Medicine recommend the use of mucolytics for secretion management when other modalities are insufficient. ${ }^{29}$ These guidelines also suggest isotonic saline for thick or dehydrated secretions, with no literature support or level of evidence provided for either recommendation. The British Thoracic Society recommends nebulized normal saline for children with NMD and tenacious secretions, although this was not based on any reported evidence. ${ }^{30}$ Included with this recommendation is the administration of a pre-dose bronchodilator to minimize bronchospasm and an initial trial to determine patient safety. However, the American College of Chest Physicians' practice guidelines on pharmacologic protussive therapy specifically state, based on a good level of evidence, that these medications should not be prescribed to promote airway clearance in patients with NMD or impairment. ${ }^{31}$

\section{Recommendation}

The use of aerosolized agents to change sputum physical properties or improve airway clearance cannot be recommended for patients with NMD or weakness due to insufficient evidence.

\section{Postoperative Adult and Pediatric Patients}

Patients undergoing surgery are at risk for postoperative pulmonary complications, including atelectasis, pneumonia, pneumothorax, pleural effusion, pulmonary emboli, ARDS, empyema, exacerbation of existing lung disease, and respiratory failure. ${ }^{32,33}$ These postoperative complications contribute to the risk of surgery, especially cardiothoracic and abdominal-wall surgery. ${ }^{33}$ The incidence is higher for patients undergoing thoracic surgery (19-59\%) than for those undergoing upper (16-20\%) or lower $(0-$ $5 \%$ ) abdominal surgery. ${ }^{34}$ Atelectasis, including subclinical atelectasis, has been reported to occur in up to $90 \%$ of all anesthetized subjects. ${ }^{35}$ It can persist for several days following surgery and, in addition to causing hypoxemia, can lead to retained secretions and pneumonia. Atelectasis can also aggravate or trigger the development of acute lung injury. ${ }^{35,36}$ Retained secretions can plug airways, leading to distal gas absorption and alveolar collapse, and are one of the causes of atelectasis in the postoperative period. ${ }^{37,38}$ Retained secretions are a primary reason given for ordering mucoactive medications.

In this systematic review, we found only 2 low-quality reports in the postoperative population; both involved the use of N-acetylcysteine. ${ }^{39,40}$ The primary outcome of interest in each study was the incidence of atelectasis. A Danish RCT compared a course of preoperative oral N-acetylcysteine and postoperative intravenous $\mathrm{N}$-acetylcysteine versus a similar strategy using a saline placebo in subjects undergoing elective upper laparotomy. ${ }^{39}$ The authors found no difference in pulmonary function or incidence of atelectasis. The second report described 2 studies involving subjects undergoing abdominal surgery. ${ }^{40} \mathrm{In}$ the first study, subjects received either intratracheal N-acetylcysteine every $2 \mathrm{~h}$ or a saline placebo. The incidence of atelectasis was $45 \%(9 / 20)$ in the placebo group versus $10 \%(2 / 20)$ in the study group. The second study com- 
pared intratracheal versus nebulized $\mathrm{N}$-acetylcysteine via an intermittent positive-pressure breathing device. The incidence of atelectasis was $20 \%(4 / 20)$ in both groups.

Two noncomparative studies of $\mathrm{N}$-acetylcysteine in postoperative thoracic surgery subjects were not included in this systematic review, as they did not meet entry criteria. ${ }^{37,41}$ One found no difference in the incidence of massive postoperative atelectasis in the nebulized $\mathrm{N}$-acetylcysteine-treated group compared with the untreated group. ${ }^{37}$ The other study found that the subjective impression of sputum viscosity and difficulty of expectoration decreased and the weight of expectorated sputum and $\mathrm{S}_{\mathrm{pO}_{2}}$ improved in the nebulized $\mathrm{N}$-acetylcysteine-treated group versus the saline-treated group during crossover. ${ }^{41}$

\section{Recommendations}

(1) Mucolytics cannot be recommended for use in the treatment of atelectasis due to insufficient evidence. (2) Routine administration of bronchodilators to postoperative patients is not recommended.

\section{Physical and Financial Harmful Effects}

The lack of evidence to support the benefit of any of the aerosolized medications listed in Table 1 does not imply that their use is benign. Adverse effects from administration of the drug or drug interactions contribute to morbidity and mortality. In addition, administering drugs that have little or no benefit to the patient contribute to the financial burden by increasing health-care costs.

Many of the studies included in the systematic review conducted by Sathe et $\mathrm{al}^{5}$ either were poor quality for reporting harm as an outcome variable or did not address adverse reactions associated with the interventional agent. Manufacturer package inserts are helpful and address the common side effects and adverse reactions. Health-care providers should be aware of these interactions with respect to the medications and assess patients for the opportunity to discontinue therapy.

Nausea, vomiting, stomatitis, fever, rhinorrhea, drowsiness, chest tightness, bronchial irritation, and, less frequently, bronchospasm in patients with known asthma are adverse effects associated with the administration of nebulized N-acetylcysteine. ${ }^{4,42}$ Bleeding at the injection site was reported as an adverse outcome in a clinical trial comparing $\mathrm{N}$-acetylcysteine administered via intratracheal instillation with nebulized $\mathrm{N}$-acetylcysteine delivered via an intermittent positive-pressure breathing device in postoperative subjects. ${ }^{40}$ This event was attributed to the invasive administration technique rather than the medication.

Adverse reactions to albuterol and ipratropium reported in the literature and by manufacturers are similar. Table 2
Table 2. Adverse Events Reported by the Manufacturers in Package Inserts for Patients Treated With 2 Commonly Used Bronchodilators

\begin{tabular}{|c|c|c|c|}
\hline \multirow[b]{2}{*}{ Adverse Reaction } & \multicolumn{3}{|c|}{$\begin{array}{l}\text { Adverse Reaction Occurring in }>3 \% \text { of } \\
\text { Subjects }(\%)\end{array}$} \\
\hline & $\begin{array}{l}\text { Ipratropium } \\
(n=219)^{*}\end{array}$ & $\begin{array}{c}\text { Ipratropium }+ \\
\text { Albuterol } \\
(n=100)^{*}\end{array}$ & $\begin{array}{l}\text { Albuterol } \\
(n=135) \dagger\end{array}$ \\
\hline \multicolumn{4}{|l|}{ Central nervous system } \\
\hline Headache & 6.4 & 9.0 & 3 \\
\hline Tremors & ND & ND & 20 \\
\hline Nervousness & ND & ND & 4 \\
\hline Dizziness & 2.3 & 4 & 7 \\
\hline \multicolumn{4}{|l|}{ Gastrointestinal } \\
\hline Nausea & 4.1 & 2 & 4 \\
\hline \multicolumn{4}{|l|}{ Ear, nose, and throat } \\
\hline Dry mouth & 3.2 & 3 & ND \\
\hline Pharyngitis & 3.7 & 4 & $<1$ \\
\hline Sinusitis & 2.3 & 4 & ND \\
\hline \multicolumn{4}{|l|}{ Cardiovascular } \\
\hline Hypertension & 0.9 & 4 & 1 \\
\hline Chest pain & 3.2 & ND & ND \\
\hline \multicolumn{4}{|l|}{ Respiratory } \\
\hline Cough & 4.6 & 6 & 4 \\
\hline Dyspnea & 9.6 & 9 & ND \\
\hline Bronchitis & 14.6 & 20 & 4 \\
\hline Bronchospasm & 2.3 & 5 & 8 \\
\hline Respiratory disorder & ND & 4 & ND \\
\hline $\begin{array}{l}\text { Upper respiratory tract } \\
\text { infection }\end{array}$ & 13.2 & 16 & ND \\
\hline \multicolumn{4}{|l|}{ General } \\
\hline Arthritis & 0.9 & 3 & ND \\
\hline Pain & 4.1 & 5 & ND \\
\hline Influenza-like symptoms & 3.7 & 1 & ND \\
\hline Back Pain & 3.2 & ND & ND \\
\hline \multicolumn{4}{|c|}{$\begin{array}{l}\text { Adverse events for albuterol were reported in all subject types. Adverse events for ipratropium } \\
\text { and a combination of albuterol and ipratropium were reported for subjects with COPD only. } \\
\text { Ipratropium was administered at } 500 \mu \mathrm{g} \text { three times/d, and albuterol was administered at } \\
2.5 \mathrm{mg} \text { three times/d. } \\
* \text { Data are from Reference } 43 . \\
\dagger \text { Data are from Reference } 44 . \\
\mathrm{ND}=\text { no data }\end{array}$} \\
\hline
\end{tabular}

provides the adverse effects reported by the manufacturers on the package inserts. Less common adverse effects that have been reported in association with ipratropium bromide use include tachycardia, palpitations, eye pain, urinary tract infections, and urinary retention. Because ipratropium bromide is an anticholinergic drug, it is not recommended for patients with narrow-angle glaucoma, prostate hypertrophy, or bladder-neck obstruction. ${ }^{43} \mathrm{Al}$ though the incidence is not reported, the manufacturer lists adverse reactions such as urticaria, angioedema, rash, bronchospasm, hoarseness, oropharyngeal edema, atrial fibrillation, supraventricular tachycardia, and extrasystole after use of albuterol inhalation solution. Repeated dosing of 
this medication has been associated with decreases in serum potassium. ${ }^{44}$

Although hypertonic saline is recommended for patients with CF, there are no studies demonstrating effectiveness in other hospitalized patient populations. Research indicates that a single treatment with hypertonic saline (most studies used 3\%) can induce bronchospasm; significantly decrease $\mathrm{FEV}_{1}(>20 \%)$ and $\mathrm{S}_{\mathrm{pO}_{2}}$; and increase vascular permeability, neutrophil adhesion, and gland secretion (neurogenic inflammation) in normal lung tissue and with pulmonary disease. ${ }^{45-48}$ These effects can occur despite pretreatment with $\beta$ agonists. ${ }^{46-52}$ The safety of giving even one treatment of hypertonic saline depends on pretreatment with $\beta$ agonists, baseline pulmonary function, previous overuse of short-acting $\beta_{2}$ agonists, nebulizer output, saline concentration, and treatment duration and frequency. ${ }^{47,48}$ Administration of bronchodilators before mucolytic administration is time-consuming, and research is lacking to establish safety, stability, and efficacy of admixtures using both agents. ${ }^{53}$

Evidence suggests that there are opportunities to constrain health-care costs without incurring adverse health consequences. ${ }^{54}$ The use of care paths, guidelines, and/or protocols provides caregivers with the opportunity to reduce unnecessary resource use and improve the value of care provided to patients by matching the therapy to patient need. When guidelines, protocols, or care paths are used, these tools establish recommendations for the initiation, titration, evaluation, and discontinuation of medications. In an assessment of the impact of the national guidelines for the treatment of hospitalized patients with bronchiolitis, McCulloh et $\mathrm{al}^{55}$ reported outcomes after the national guidelines for bronchiolitis were implemented at 2 academic medical centers. Fewer children received a trial of racemic epinephrine $(17.8 \%$ vs $12.2 \%, P=.006)$ or albuterol sulfate $(81.6 \%$ vs $72.6 \%, P<.001)$, and albuterol sulfate was discontinued more often after guidelines were instated $(28.6 \%$ vs $78.9 \%, P<.001)$. Corticosteroid use in children without a history of asthma decreased with guideline use $(26.5 \%$ vs $17.5 \%, P<.001) .{ }^{55}$ The use of such tools improves the cost effectiveness and care coordination by targeting therapeutic interventions to the patients who would benefit the most.

\section{Discussion}

Although it has been stated that absence of evidence is not the same as absence of effectiveness, even the weak studies identified in this systematic review do not support the use of bronchodilator or mucoactive medication when treating or attempting to prevent pulmonary complication in adults or children without $\mathrm{CF}$ who are admitted to the hospital. Although it is tempting to extrapolate from the effective use of some mucoactive mediations to enhance airway clearance in persons with $\mathrm{CF}$ to those without $\mathrm{CF}$, it appears that, to date, not only has this approach proven unsuccessful, but, in many cases, it has been harmful. All caregivers are aware of the critical dictum to first, do no harm (primum non nocere). Harm comes in many forms, including physical harm, waste of resources such as time and money, and intellectual harm, where clinical wisdom trumps clinical evidence. We strongly believe that these considerations should drive evidence-based respiratory care practice.

This is not to suggest that there could be no value in using effective mucoactive medications to improve airway clearance and prevent complications such as atelectasis. However, what is lacking are well designed, appropriately powered RCTs with clinically meaningful outcome measurements of both existing and novel mucoactive medications, alone or in combination with airway clearance devices.

\section{Implications and Directions for Future Research}

In theory, using medications to improve airway clearance should be an acceptable practice. However, the evidence supporting current practice is exceptionally limited. ${ }^{5}$ $\beta$ agonists can increase ciliary beat frequency in healthy subjects, but the impact on mucus clearance in subjects with pulmonary disease is not significant. ${ }^{56,57}$ As mucoregulatory agents, anticholinergic medications may reduce mucus secretion, but the evidence demonstrates no improvement in mucus clearance in patients with or without pulmonary disease. ${ }^{13}$ Some mucoactive medications improve mucus clearance when used in patients with $\mathrm{CF}$, but the evidence does not support the use of these medications for patients with non-CF pulmonary disease..$^{58-61}$ Novel therapies to improve mucus clearance in unique situations, such as burns and inhalation injuries, have shown promise, but the amount of evidence is small, and more investigation is necessary before making definitive recommendations. $^{7}$

The lack of high-level evidence has a significant impact on the respiratory therapist's ability to recommend for or against using inhaled medications to improve mucus clearance. Clinical decision making should be based on individual patient need, response to therapy, and potential for harm. Future research should be designed carefully with regard to subject population, outcome measures, and intervention. ${ }^{62,63}$

\section{ACKNOWLEDGMENTS}

We acknowledge the significant contribution of Ms Nila Sathe, Ms Shanthi Krishnaswami, Ms Cathy Ficzere, Dr Jeff Andrews, and Dr Melissa McPheeters (Vanderbilt Evidence-based Practice Center, Nashville, Tennessee); Dr Dean Hess (Massachusetts General Hospital and Harvard 


\section{AarC Clinical Practice Guideline: Airway Clearance Therapies}

Medical School, Boston, Massachusetts); and Mr Richard Branson (University of Cincinnati College of Medicine, Cincinnati, Ohio).

\section{REFERENCES}

1. Foster WM. Mucociliary transport and cough in humans. Pulm Pharmacol Ther 2002;15(3):277-282.

2. Zaugg M, Lucchinetti E. Respiratory function in the elderly. Anesthesiol Clin North America 2000;18(1):47-58.

3. Hernandez ML, Harris B, Lay JC, Bromberg PA, Diaz-Sanchez D, Devlin RB, et al. Comparative airway inflammatory response of normal volunteers to ozone and lipopolysaccharide challenge. Inhal Toxicol 2010;22(8):648-656.

4. Rogers DF. Mucoactive agents for airway mucus hypersecretory diseases. Respir Care 2007;52(9):1176-1193; discussion 1193-1197.

5. Sathe NA, Krishnaswami S, Andrews J, Ficzere C, McPheeters ML. Pharmacologic agents that promote airway clearance in hospitalized patients: a systematic review. Respir Care 2015;60(7):1061-1070.

6. Strickland SL, Rubin BK, Drescher GS, Haas CF, O'Malley CA, Volsko TA, et al. AARC Clinical Practice Guideline: effectiveness of nonpharmacologic airway clearance therapies in hospitalized patients. Respir Care 2013;58(12):2187-2193.

7. Flume PA, Robinson KA, O'Sullivan BP, Finder JD, Vender RL, Willey-Courand DB, et al. Cystic fibrosis pulmonary guidelines: airway clearance therapies. Respir Care 2009;54(4):522-537.

8. Park GY, Park JW, Jeong DH, Jeong SH. Prolonged airway and systemic inflammatory reactions after smoke inhalation. Chest 2003; 123(2):475-480

9. Zorc JJ, Hall CB. Bronchiolitis: recent evidence on diagnosis and management. Pediatrics 2010;125(2):342-349.

10. Maselli R, Paciocco G. Asthma: pathophysiology of the bronchial obstruction. Allergy 2000;55(Suppl 61):49-51.

11. Milne S, King GG. Advanced imaging in COPD: insights into pulmonary pathophysiology. J Thorac Dis 2014;6(11):1570-1585.

12. Rubin BK. The pharmacologic approach to airway clearance: mucoactive agents. Paediatr Respir Rev 2006;7(Suppl 1):S215-S219.

13. Desai MH, Mlcak R, Richardson J, Nichols R, Herndon DN. Reduction in mortality in pediatric patients with inhalation injury with aerosolized heparin/ $\mathrm{N}$-acetylcystine therapy. J Burn Care Rehabil 1998;19(3):210-212.

14. Pulle DF, Glass P, Dulfano MJ. A controlled study of the safety and efficacy of acetylcysteine-isoproterenol combination. Curr Ther Res Clin Exp 1970;12(8):485-492.

15. Pasteur MC, Bilton D, Hill AT. British Thoracic Society guideline for non-CF bronchiectasis. Thorax 2010;65(Suppl 1):i1-i58.

16. Qaseem A, Wilt TJ, Weinberger SE, Hanania NA, Criner G, van der Molen $\mathrm{T}$, et al. Diagnosis and management of stable chronic obstructive pulmonary disease: a clinical practice guideline update from the American College of Physicians, American College of Chest Physicians, American Thoracic Society, and European Respiratory Society. Ann Int Med 2011;155(3):179-191.

17. Bye PT, Lau EM, Elkins MR. Pharmacologic airway clearance strategies in bronchiectasis. Eur Respir Monogr 2011;52:239-247.

18. Haas CF, Loik PS, Gay SE. Airway clearance applications in the elderly and in patients with neurologic or neuromuscular compromise. Respir Care 2007;52(10):1362-1381; discussion 1381.

19. McCool FD. Global physiology and pathophysiology of cough. Chest 2006;129(1 Suppl):48S-53S.

20. Boitano LJ. Management of airway clearance in neuromuscular disease. Respir Care 2006;51(8);913-22; discussion 922-924.

21. Berlly M, Shem K. Respiratory management during the first five days after spinal cord injury. J Spinal Cord Med 2007;30(4):309318
22. Arora S, Flower O, Murray NP, Lee BB. Respiratory care of patients with cervical spinal cord injury: a review. Crit Care Resusc 2012; 14(1):64-73.

23. Finder JD. A 2009 perspective on the 2004 American Thoracic Society Statement, "respiratory care of the patient with Duchenne muscular dystrophy. Pediatrics 2009;123(Suppl 4):S239-S241.

24. Livraghi A, Randell SH. Cystic fibrosis and other respiratory diseases of impaired mucus clearance. Toxicol Pathol 2007;35(1):116129.

25. Fahy JV, Dickey BF. Airway mucus function and dysfunction. NEJM 2010;363(23):2233-2247.

26. Oberwaldner B. Physiotherapy for airway clearance in paediatrics. Eur Respir J 2000;15(1):196-204.

27. Finder JD, Birnkrant D, Carl J, Farber HJ, Gozal D, Iannaccone ST, et al. Respiratory care of the patient with Duchenne muscular dystrophy. Am J Respir Crit Care Med 2004;170(4):456-465.

28. Miller RG, Jackson CE, Kasarskis EJ, England JD, Forshew D, Johnston W, et al. Practice parameter update: the care of the patient with amyotrophic lateral sclerosis: drug, nutritional, and respiratory therapies (an evidence-based review). Neurology 2009;73(15):12181226.

29. Birnkrant DJ, Bushby KM, Amin RS, Bach JR, Benditt JO, Eagle M, et al. The respiratory management of patients with Duchenne muscular dystrophy: a DMD care considerations working group specialty article. Pediatr Pulmonol 2010;45(8):739-748.

30. Bott J, Blumenthal S, Buxton M, Ellum S, Falconer C, Garrod R, et al. Guidelines for the physiotherapy management of the adult, medical, spontaneously breathing patient. Thorax 2009;64(Suppl 1):i1i51.

31. Bolser DC. Cough suppressant and pharmacologic protussive therapy. Chest 2006;129(1 Suppl):238S-249S.

32. Sabaté S, Mazo V, Canet J. Predicting postoperative pulmonary complications: implications for outcomes and cost. Curr Opin Anaesthesiol 2014;27(2):201-209.

33. Shander A, Fleisher LA, Barie PS, Bigatello LM, Sladen RN, Watson $\mathrm{CB}$. Clinical and economic burden of postoperative pulmonary complications: patient safety summit on definition, risk-reducing interventions, and prevention strategies. Crit Care Med 2011;39(9): 2163-2172.

34. Sachdev G, Napolitano LM. Postoperative pulmonary complications: pneumonia and acute respiratory failure. Surg Clin North Am 2012; 92(2):321-344

35. Hedenstierna G, Edmark L. Mechanisms of atelectasis in the perioperative period. Best Pract Res Clin Anaesthesiol 2010;24(2):157169.

36. Muders T, Wrigge H. New insights into experimental evidence on atelectasis and causes of lung injury. Best Pract Res Clin Anaesthesiol 2010;24(2):171-182.

37. Silvola HJ, Salonen I, Tala P. Acetylcystine inhalations and postoperative atelectasis in thoracic surgery. Ann Chir Gynaecol Fenn 1967; 56(2):233-236

38. Kreider ME, Lipson DA. Bronchoscopy for atelectasis in the ICU: a case report and review of the literature. Chest 2003;124(1):344-350.

39. Jepsen S, Klaerke A, Nielsen PH, Nielsen ST, Simonsen O. Systemic administration of $\mathrm{N}$-acetylcystine has no effect on postoperative lung function following elective upper laparotomy in lung healthy patients. Acta Anaesthesiol Scand 1989;33(3):219-222.

40. Thomas PA, Lynch RE, Merrigan EH. Prevention of postoperative pulmonary atelectasis: review of 215 cases and evaluation of acetylcystine. Am Surgeon 1966;32(5):301-307.

41. Gallon AM. Evaluation of nebulized acetylcystine and normal saline in the treatment of sputum retention following thoracotomy. Thorax 1996;51(4):429-432. 


\section{AarC Clinical Practice Guideline: Airway Clearance Therapies}

42. Acetylcysteine: package insert and label information. http://druginserts.com/lib/rx/meds/acetylcysteine-7. Accessed January 25, 2015.

43. Ipratropium bromide inhalation solution $0.02 \%$ package insert. Columbia, SC: Ritedose Pharmaceuticals; 2013.

44. Albuterol sulfate inhalation solution $0.5 \%$ package insert. Tampa, FL: Bausch \& Lomb; 2013.

45. Umeno E, McDonald DM, Nadel JA. Hypertonic saline increases vascular permeability in the rat trachea by producing neurogenic inflammation. J Clin Invest 1990;85(6):1905-1908.

46. Taube C, Holz O, Mücke M, Jörres RA, Magnussen H. Airway response to inhaled hypertonic saline in patients with moderate to severe chronic obstructive pulmonary disease. Am J Respir Crit Care Med 2001;164(10):1810-1815.

47. Pizzichini E, Pizzichini MM, Leigh R, Djukanović R, Sterk PJ. Safety of sputum induction. Eur Respir J 2002;20(37 Suppl):9s-18s.

48. Rytilä $\mathrm{PH}$, Lindqvist $\mathrm{AE}$, Laitinen LA. Safety of sputum induction in chronic obstructive pulmonary disease. Eur Respir J 2000;15(6): 1116-1119.

49. Wong HH, Fahy JV. Safety of one method of sputum induction in asthmatic subjects. Am J Respir Crit Care Med 1997;156(1):299303.

50. Hunter CJ, Ward R, Woltmann G, Wardlaw AJ, Pavord ID. The safety and success rate of sputum induction using a low output ultrasonic nebuliser. Respir Med 1999;93(5):345-348.

51. Pizzichini MM, Pizzichini E, Clelland L, Efthimiadis A, Mahony J, Dolovich J, Hargreave FE. Sputum in severe exacerbations of asthma: kinetics of inflammatory indices after prednisone treatment. Am J Respir Crit Care Med 1997;155(5):1501-1508.

52. Vlachos-Mayer H, Leigh R, Sharon RF, Hussack P, Hargreave FE. Success and safety of sputum induction in the clinical setting. Eur Respir J 2000;16(5):997-1000.
53. Burchett DK, Darko W, Zahra J, Noviasky J, Probst L, Smith A. Mixing and compatibility guide for commonly aerosolized medications. Am J Health Syst Pharm 2010;73(3):227-230.

54. Orszag PR, Ellis P. Addressing rising health care costs—a view from the Congressional Budget Office. N Engl J Med 2007;357(19):18851887.

55. McCulloh RJ, Smitherman SE, Koehn KL, Alverson BK. Assessing the impact of national guidelines on the management of children hospitalized for acute bronchiolitis. Pediatr Pulmonol 2014;49(7): 688-694.

56. Rubin BK. Mucus, phlegm, and sputum in cystic fibrosis. Respir Care 2009;54(6):726-732; discussion 732 .

57. Restrepo RD. Inhaled adrenergics and anticholinergics in obstructive lung disease: do they enhance mucociliary clearance? Respir Care 2007;52(9):1159-1173; discussion 1173-1175.

58. Rubin BK. Mucolytics, expectorants, and mucokinetic medications. Respir Care 2007;52(7):859-865.

59. Rubin BK. Pediatric aerosol therapy: new devices and new drugs. Respir Care 2011;56(9):1411-1421; discussion 1421-1423.

60. Judson MA, Chaudhry H, Compa DR, O'Donnell AE. A Delphi study of pharmacotherapy for non-cystic fibrosis bronchiectasis. Am J Med Sci 2014;348(5):387-393

61. Hart A, Sugumark K, Milan SJ, Fowler SJ, Crossingham I. Inhaled hyperosmolar agents for bronchiectasis. Cochrane Database Syst Rev 2014;5:CD002996.

62. Rubin BK. Designing clinical trials to evaluate mucus clearance therapy. Respir Care 2007;52(10):1348-1358; discussion 1358-1361.

63. Donaldson SH, Corcoran TE, Laube BL, Bennett WD. Mucociliary clearance as an outcome measure for cystic fibrosis clinical research. Proc Am Thorac Soc 2007;4(4):399-405. 